\title{
O DANO EXISTENCIAL NAS RELAÇÕES \\ DE TRABALHO E A EFICÁCIA HORIZONTAL \\ DOS DIREITOS FUNDAMENTAIS NAS \\ RELAÇÕES PRIVADAS
}

Vanessa Rocha Ferreira ${ }^{1}$

THE EXISTENTIAL DAMAGE IN LABOR RELATIONS AND

THE HORIZONTAL EFFECTIVENESS OF FUNDAMENTAL

RIGHTS IN THE PRIVATE RELATIONS

RESUMO: Indiscutivelmente os direitos fundamentais vinculam tanto o Estado, quanto o particular. Tendo por base essa eficácia horizontal dos direitos fundamentais nas relações privadas, o presente artigo se propõe a discutir o dano existencial na seara laboral, que é o dano criado pela violação do direito à existência da própria pessoa, ou seja, pela frustração de seus projetos de vida em decorrência da superexploração causada pelo empregador. Será feita uma análise do direito ao lazer e do direito ao trabalho como requisitos necessários à existência digna de qualquer trabalhador, com a possibilidade de se pleitear este dando, quando o empregador exige deliberadamente e de forma contumaz do trabalhador mais do que seria possível, de forma remunerada ou não, o impedindo de usufruir de outros aspectos de sua existência.

Palavras-chave: Dano existencial. Relações de trabalho. Eficácia horizontal. Direitos Fundamentais. Relações Privadas.
ABSTRACT: Without a doubt, fundamental rights are binding on both the State and the private. Based on this horizontal effect of fundamental rights in private relationships, this article aims to discuss the existential damage in labor harvest, which is the damage created by the violation of the right to existence of the person, or the frustration of your projects of life as a result of overexploitation caused by the employer. It will be an analysis of the right to leisure and the right to work as requirements for dignified existence of all workers, with the possibility to plead this giving, when the employer deliberately demands and worker contumacious more than would be possible, remunerated or not, stopping to enjoy other aspects of your existence.

Keywords: Existential damage. Labor relations. Fundamental rights. Horizontal effect. Private relationships.

\footnotetext{
${ }^{1}$ Doutora em Direitos Humanos pela Universidade de Salamanca (Espanha). Mestranda em Direitos Fundamentais pela Universidade da Amazônia (UNAMA/PA). Pós-Graduada em Direito Público pela Universidade Cândido Mendes (UCAM/RJ). Especialista em Direito Processual pela Universidade da Amazônia (UNAMA/PA). Advogada. Professora Universitária (UNAMA/PA). Vice coordenadora do Departamento de Direito do Trabalho da Escola Superior de Advocacia (ESA - OAB/PA. E-mail: vanessarochaf@gmail.com.
} 


\section{INTRODUÇÃO}

Recentemente a doutrina e a jurisprudência vêm discutindo sobre o surgimento de uma nova espécie de dano imaterial: o dano existencial.

No direito do trabalho, a ocorrência deste dano é vislumbrada sempre que o empregador utiliza-se de seu poder diretivo para exigir do trabalhador um trabalho excessivo, desrespeitando as limitações de jornadas estabelecidas pelo ordenamento jurídico vigente, ou as regras de segurança e medicina do trabalho, ocasionando um prejuízo à existência do trabalhador, ao seu plano de vida, à sua convivência familiar e social.

O que se pretende fazer neste ensaio é analisar como tal dano vem sendo tratado no direito trabalhista brasileiro, e, ao mesmo tempo, defender que se trata de uma nova modalidade de dano imaterial, diversa do dano moral, com elementos caracterizadores e objetos de proteção distintos, sendo cabível inclusive a cumulação dessas duas espécies de dano, para que haja uma correta reparação da lesão sofrida pelo indivíduo.

Para tanto utilizaremos o método dedutivo no ensejo de melhor analisar como a doutrina e a jurisprudência tem se posicionado no que tange a este tema, além de pesquisa bibliográfica e descritiva acerca dessa nova espécie de dano na seara laboral.

Primeiramente será feita uma análise da penetrabilidade dos direitos fundamentais nas relações privadas, para destacar a importância de se resguardar o direito ao trabalho, exigindo-se que o empregador cumpra com o regramento básico estabelecido na Constituição Federal Brasileira (CRFB/88).

Posteriormente discutiremos o direito ao não trabalho e o direito ao lazer como elementos necessários para a busca da felicidade do indivíduo, para que neste tempo livre ele possa desenvolver os diversos aspectos de sua personalidade. 
Por fim, defenderemos, na continuação, que os limites temporais estabelecidos no ordenamento jurídico para o trabalho devem ser respeitados, pois estão diretamente relacionados à saúde física e mental do trabalhador, e que quando não o são, deliberada e reiteradamente, causam prejuízos ao trabalhador; esta conduta pode dar ensejo a uma indenização decorrente do dano existencial.

\section{EFICÁCIA DOS DIREITOS FUNDAMENTAIS NAS RELAÇÕES PRIVADAS DE TRABALHO}

Diferentemente do que acontecia a época do Estado Liberal, onde se defendia a separação entre o direito público e o direito privado, com o advento do Estado Social, a Constituição Federal passou a ser o cerne do sistema jurídico, consagrando valores como a solidariedade e direitos oponíveis aos atores privados (a exemplo dos direitos trabalhistas), reconhecendo-se a sua força normativa ${ }^{2}$, ou seja, a possibilidade de conteúdos normativos serem diretamente extraídos dos preceitos constitucionais.

[...] Com o advento do Estado Social, passou-se a reconhecer a necessidade de intervenção do Estado, através de políticas públicas, para proteção dos mais débeis diante do arbítrio dos mais fortes, e de garantia das condições materiais básicas de existência, [...] (SARMENTO, 2006, p. 62).

Diante disto, o ordenamento passou a ser visto como uma unidade, no qual a Lei Maior representa um limite para o legislador, mas também estabelece uma direção a seguir. (SARMENTO, 2003, p. 86).

Assim, os direitos fundamentais, em termos de eficácia passaram a ser analisados em duas dimensões: a objetiva e a subjetiva.

A dimensão objetiva, onde se reconhece que os direitos fundamentais tem eficácia de determinar a interpretação do ordenamento jurídico à luz desse valor, o que é fundamental para o direito do trabalho, pois passamos a fazer a leitura das normas trabalhistas à luz dos direitos fundamentais, vinculando o Estado em relações com

\footnotetext{
${ }^{2}$ Sobre a força normativa da Constituição recomenda-se a leitura de Konrad Hesse (1991), a força normativa da Constituição.
} 
particulares (eficácia vertical dos direitos fundamentais ${ }^{3}$ ) e os particulares em relações com outros particulares (eficácia horizontal dos direitos fundamentais ${ }^{4}$ ), desta forma estão todos obrigados a respeitar, promover e proteger os direitos fundamentais.

A dimensão subjetiva, pela qual, tais direitos se traduzem em direitos subjetivos passíveis de serem exigidos e judicializados, ou seja, todo direito fundamental gera ao titular desse direito uma possibilidade de poder buscar, quando houver violação, uma tutela jurisdicional, no caso de ameaça ou lesão.

Note-se que o Estado não é o único capaz de ocasionar danos aos particulares, no âmbito das relações privadas o desrespeito aos direitos fundamentais também pode ocorrer, sendo muito comum na seara laboral, na qual o trabalhador é hipossuficiente em face de seu empregador.

Sobre o tema escreve Cifuentes Munõz (1998, p. 12).:

[...] certas normas sobre direitos fundamentais dotam o cidadão de um status socialis que o ordenamento constitucional garante frente aos particulares e, em especial, em relação com os grandes poderes econômicos e sociais o qual vem a compensar sua relativa precariedade.

Ponto importante a ser destacado refere-se à cláusula geral de tutela da pessoa humana que se materializa, em nossa Constituição, através do princípio da dignidade humana, que assegura à pessoa o reconhecimento de direitos pré-existentes pelo simples fato de serem humanos, ratificando a penetração dos direitos fundamentais nas relações privadas.

[...] hoje, a eficácia dos direitos e liberdades fundamentais nas relações de direito

\footnotetext{
${ }^{3}$ Neste ponto discute-se a vinculação positiva dos poderes públicos aos direitos fundamentais de modo que o cidadão deve ter segurança no sentido de que o Estado não invadirá a esfera de sua liberdade individual (vinculação negativa) ao mesmo tempo em que deve ter a certeza de que poderá utilizar adequadamente as situações vantajosas que lhe são asseguradas abstratamente no ordenamento jurídico, caso contrário poderá contar com a intervenção judicial para a plena realização de seus direitos (AMARAL, 2014, p. 68).

${ }^{4}$ No que tange aos particulares, existe apenas a vinculação negativa, ou seja, os indivíduos devem se abster de qualquer prática que viole a Constituição, não podendo vulnerar direitos e garantias individuais de outros cidadãos. Vide Sentenças n. 101/1981, de 18 de novembro, e n. 177/1988, de 10 de outubro, do Tribunal Constitucional da Espanha. Disponível em: www.tribunalconstitucional.es. Acesso em 20 de jul. 2015.
} 
privado é, pois, exigida, por um lado, pela 'dignidade da pessoa humana' encarada no quadro do Estado Social e Democrático de Direito e, por outro, pela nova 'dimensão objetiva' atualmente reconhecida àqueles direitos (ABRANTES, 2005, p. 72, grifo nosso).

Convém mencionar que esse princípio está ligado ao direito ao livre exercício da profissão, e que também é preciso ser respeitado pelo empregador. Neste sentido temos o interessante julgado do Desembargador Dr. José Felipe Ledur:

Os direitos fundamentais previstos no art. 70 da Constituição de 1988, dentre eles o disposto no inciso XIII (duração do trabalho normal não superior a oito horas diárias e quarenta e quatro semanais, facultada a compensação de horários e a redução da jornada, mediante acordo ou convenção coletiva de trabalho) e no inciso XXII (redução dos riscos inerentes ao trabalho, por meio de normas de saúde, higiene e segurança) são concreções de valores e normas de caráter principiológico e correspondem a uma decisão jurídico-objetiva de valor adotada pela Constituição. Esta prevê valores e princípios, dentre outros, no Preâmbulo (e.g., a asseguração do exercício dos direitos sociais, da liberdade e do bem-estar), no art. 1으. III e IV (dignidade da pessoa humana os valores sociais do trabalho e da livre-iniciativa) e no rol dos direitos sociais elencados no art. 6o (e.g., o direito à saúde, ao trabalho, ao lazer e à segurança). Do princípio da dignidade da pessoa humana, núcleo dos direitos fundamentais em geral, decorre o direito ao livre desenvolvimento da personalidade do trabalhador, nele abarcado o desenvolvimento profissional mencionado no art. 5으, XIII, da Constituição, o que exige condições dignas de trabalho e observância dos direitos fundamentais assegurados aos trabalhadores. Finalmente, esses valores e princípios vinculam não só o Estado (eficácia vertical dos direitos fundamentais), mas também o empregador/organização econômica (eficácia horizontal dos direitos fundamentais ou eficácia em face dos particulares). (grifo nosso) Rio Grande do Sul, TRT, RO 105-14.2011.5.04.0241. Relator Des. José Felipe Ledur, 1ạ Turma, Diário Eletrônico da Justiça do Trabalho, Porto Alegre, 3 jun. 2011.

Assim, destaca-se a importância da proteção do Princípio da dignidade humana tanto nas relações públicas quanto nas relações privadas, pois o que se visa proteger é o valor da pessoa humana, a sua dignidade. Neste sentido:

Como regra daí decorrente, pode-se dizer que, em todas as relações privadas nas quais venha a ocorrer um conflito entre uma situação jurídica subjetiva existencial e uma situação jurídica patrimonial, a primeira deve prevalecer, obedecidos assim, os princípios constitucionais que estabelecem a dignidade da pessoa humana como valor cardeal do sistema (MORAES, 2003, p. 120). 
Aqui resta claro que o princípio fundamental da dignidade humana deve ser respeitado em qualquer nível de relação que se estabeleça entre os indivíduos, sendo cabível uma indenização em caso de sua violação. Neste sentido, afirma CAVALIERI (s.d.a, p.56 apud MORAES, 2003, p.131-132): “[d]ano moral, à luz da Constituição vigente, nada mais é do que violação do direito à dignidade."

Por fim, convém ainda destacar a importância da penetração dos direitos fundamentais nas relações laborais, pois uma vez que a Constituição sirva de parâmetro para a relação jurídica que se estabelece entre os particulares e seja respeitada, estaremos diante de uma proteção mais efetiva ao trabalhador que é a parte mais frágil dessa relação.

Em regra, os contratos de trabalho traduzem uma relação na qual há uma flagrante desigualdade entre as partes, pois de um lado temos o empregador, detentor do poder diretivo, e econômico, e do outro o trabalhador, que possui somente a sua força de trabalho, e é a parte mais vulnerável deste, exatamente por este motivo é que atualmente se fala na "constitucionalização do direito do trabalho", com o intuito de fazer uma leitura constitucional deste ramo do direito a fim de assegurar ao trabalhador o respeito aos seus direitos fundamentais e à sua dignidade no âmbito da relação laboral.

\section{DIREITO DO TRABALHO}

Consagrado como um direito social fundamental no art. 6o da Constituição da República Federativa do Brasil, o direito ao trabalho é um dos principais elementos para que o ser humano possa usufruir de uma existência digna, pois é através do trabalho que o ser humano consegue o mínimo necessário para realizar o seu plano de vida e possa existir dignamente. Exatamente por esse motivo, que a Constituição Federal prevê o regramento mínimo para que o trabalho seja prestado em equilíbrio com a vida da pessoa, assegurando em seu art. 70 diversas prerrogativas aos trabalhadores urbanos e rurais, consoante exposto nos 34 incisos do aludido dispositivo constitucional. 
Importante destacar que, conforme entendem Gilmar Mendes e Paulo Branco (2012, p. 694), as garantias elencadas no art. 70 da CRFB/88 não são direcionadas apenas ao legislador e ao gestor público, como também ao empregador, tratando-se, “[...] em muitos casos, de aplicação direta de norma de caráter fundamental às relações privadas", como foi discutido no tópico anterior.

Deste modo, as regras estabelecidas na Constituição devem ser observadas tanto pelo Estado quanto pelo particular, sob pena de violar a cláusula geral de tutela da pessoa humana, que se materializa no princípio da dignidade humana.

Para que o direito ao trabalho seja respeitado é preciso considerar a qualidade de vida da pessoa, tanto no ambiente laboral quanto fora dele. É preciso que esse trabalho seja adequado, digno, para que o indivíduo consiga ter a sua integridade (integralidade) respeitada. O prof. Dr. Brito Filho (2013, p. 55) denomina este trabalho de trabalho decente, e assim dispõe:

Trabalho decente, então, é um conjunto mínimo de direitos do trabalhador que corresponde: (i) ao direto ao trabalho; (ii) à liberdade de trabalho; (iii) à igualdade no trabalho; (iv) ao trabalho com condições justas, incluindo a remuneração e que preservem sua saúde e segurança; (v) à proibição do trabalho infantil; (vi) à liberdade sindical; e (vii) à proteção contra os riscos sociais.

O homem que trabalha sem limites, exaustivamente é mero objeto, perdendo o sentido da sua existência, o que é incompatível com a ideia de dignidade humana, como já defendia Kant há décadas: "o ser humano tem dignidade e não preço".

Com base no exposto passamos então a defender o direito ao não trabalho, como um desdobramento do direito social ao lazer. 


\section{PROTEÇÃO AO NÃO TRABALHO E O DIREITO AO LAZER}

Constitucionalmente previsto no art. 6o da $\mathrm{CRFB} / 88^{5}$, o direito ao lazer é uma questão filosófica e cultural, que se traduz no tempo que o ser humano tem além do trabalho, tempo para entretenimento, para usufruir de sua existência, para desfrutar da convivência familiar e social, para desenvolver as atividades que deseja, como, por exemplo, praticar esportes ou fazer teatro, pintura, música.

Neste sentido escreve Nascimento (2009, p. 488):

[...] o lazer atende à necessidade de liberdade, de compensação da vida contemporânea e é uma resposta à violência que se instaurou na sociedade, ao isolamento, à necessidade do ser humano de encontrar-se consigo e com o próximo, sendo essas, entre outras, as causas que levam a legislação a disciplinar a duração do trabalho e os descansos obrigatórios.

Neste mesmo sentido escreve Franco Filho (2015, p. 53):

Devemos entender como aquele que possui a pessoa humana de usar seu tempo livre em atividades e ações que the sejam prazerosas, não necessariamente relacionadas ao trabalho, porquanto deve ser aquele disponível para a convivência familiar, prática esportiva ou alguma atividade artística, intelectual ou simplesmente o ócio.

Infelizmente no Brasil, a ideia de direito ao lazer é relacionada de forma pejorativa ao não trabalho, porém tal direito precisa ser analisado por outro prisma, pois possui aspectos muito importantes para a existência humana.

No dizer de Oliveira (2012, p. 182) a eficácia do direito ao lazer estaria diretamente relacionada à dignidade do trabalhador, pois tal direito tem por objetivo, dentre outros, melhorar a qualidade de vida do obreiro, pois é por meio do direito ao lazer, que o trabalhador adquire o direito à desconexão (ALMEIDA; SEVERO, 2015).

Note-se que o direito ao lazer está relacionado a diversos aspectos. Tem-se a questão fisiológica, a dimensão humana que reconhece como uma necessidade biológica o

\footnotetext{
${ }^{5}$ Recomenda-se a leitura dos art. 70, IV; 213 , § 3ㅇ e 227, caput da CRFB/88, que também fazem menção ao direito ao lazer.
} 
descanso, tem uma dimensão social, pois é no momento de descanso ocorre a convivência social e familiar, tem uma dimensão psíquica e existencial, pois é durante o lazer que eu dou sentido a minha existência, e alcanço a felicidade.

Neste ponto, introduzimos na discussão o posicionamento do Prof. Dr. Franco Filho que entende que o direito ao lazer está diretamente relacionado à busca da felicidade, defendendo o direito social à felicidade ${ }^{6}$, como uma forma de efetivar os demais direitos sociais e melhorar a qualidade de vida das pessoas E dispõem: "Com isso todos os direitos sociais passam a ser essenciais à busca da felicidade. Se implementarmos, darão chance ao direito social à felicidade, que assim será o maior de todos, porque representará o somatório deles" (FRANCO FILHO, 2014, p.142).

Desta forma, percebemos que o direito ao lazer deve proteger todas essas dimensões da existência humana, sendo através dele que se alcança a felicidade, que no dizer de Soares (2009, p.37) seria a razão de ser da existência humana.

\section{O DANO EXISTENCIAL}

Os institutos criados pelo direito laboral existem exatamente para equilibrar a relação existente entre a vida e o trabalho das pessoas, permitindo que essas pessoas tenham qualidade de vida satisfatória. São exemplos de institutos que tentam conciliar esses dois direitos fundamentais (vida-trabalho): a limitação da jornada de trabalho, os períodos de descanso, as férias etc.

A hiperexploração do trabalhador com o desrespeito a esses direitos causa um prejuízo à saúde do trabalhador, e também o impede de desfrutar dos prazeres de sua

\footnotetext{
${ }^{6} \mathrm{O}$ direito social à felicidade já é realidade em alguns ordenamentos jurídicos como por exemplo: no Japão (art. 13 da Constituição de 03.11.1946), na Coreia (art. 10 da Carta da Coreia do Sul de 17.07.1948) e no Butão (art. 9o, 2o de sua Constituição). No Brasil tramita no Congresso Nacional a PEC n. 19/2010, apresentada pelo Sen. Cristovão Buarque que propõe uma nova redação ao artigo 60 da CF: São direitos sociais, essenciais à busca da felicidade, a educação, a saúde, a alimentação, o trabalho, a moradia, o lazer, a segurança, a previdência social, a proteção à maternidade e à infância, a assistência aos desamparados na forma desta Constituição (FRANCO FILHO, 2014, p. 141).
} 
própria existência, de ordem biológica, econômica, cultural e social, o que usualmente vem sido denominado pela doutrina e jurisprudência como dano existencial.

\subsection{Origem e conceituação}

O dano existencial tem sua origem na Decisão no 7.713, de 07 de junho de 2000, da Corte Suprema da Itália, que pela primeira vez o reconheceu explicitamente.

Trata-se de dano de natureza imaterial, que afeta diretamente a existência da pessoa, causando-Ihe a impossibilidade de desenvolver o seu plano de vida, privando-Ihe da convivência familiar ou em sociedade, ofendendo diretamente a sua dignidade.

Neste sentido o define Frota (2013, p. 63):

O dano existencial constitui espécie de dano imaterial ou não material que acarreta a vítima, de modo parcial ou total, a impossibilidade de executar, dar prosseguimento ou reconstruir o seu projeto de vida (na dimensão familiar, afetivo-sexual, intelectual, artística, científica, desportiva, educacional ou profissional, dentre outras) e a dificuldade de retomar sua vida de relação (de âmbito público ou privado, sobretudo na seara da convivência familiar, profissional ou social).

Flaviana Rampazzo Soares o define como:

[...] é a lesão ao complexo de relações que auxiliam no desenvolvimento normal da personalidade do sujeito, abrangendo a ordem pessoal ou a ordem social. É uma afetação negativa, total ou parcial, permanente ou temporária, seja a uma atividade, seja a um conjunto de atividades que a vítima do dano, normalmente, tinha como incorporado em seu cotidiano e que, em razão do efeito lesivo precisou modificar em sua forma de realização, ou mesmo suprimir de sua rotina (SOARES, 2009, p. 44).

Assim, entendemos ser o dano existência um dano de cunho imaterial, desvinculado do prejuízo econômico, que causa uma lesão ao plano de vida do indivíduo, a sua existência. 


\subsection{Configuração}

Para que seja configurado o dano existencial, além dos requisitos essenciais para configurar qualquer dano, previstos no art. 186 e 187 do Código Civil (prejuízo, ato ilícito e nexo de causalidade), faz-se necessário que haja um prejuízo à própria existência humana, ao plano de vida do trabalhador e as relações familiares.

[...] decorre da conduta patronal que impossibilita o empregado de ser relacionar e de conviver em sociedade por meio de atividades criativas, afetivas, espirituais, culturais, esportivas, sociais e de descanso, que lhe trarão bem-estar físico e psíquico e, por consequência, felicidade, ou que o impede de executar, de prosseguir ou mesmo de recomeçar os seus projetos de vida, que serão, por sua vez, responsáveis pelo seu crescimento ou realização profissional, social e pessoal (ALVARENGA, BOUCINHAS Jr., 2013, p. 33).

Note que para que se configure tal dano faz-se necessário que o desrespeito às regras laborais seja repetitivo, contumaz, não bastando o descumprimento pontual da legislação trabalhista. Em verdade, é necessário que fique configurado um dano à existência do trabalhador, ao seu convívio social, familiar. No dizer de Júlio Cézar Bebber (2009, p. 28) é necessário "[provocar] um vazio existencial na pessoa que perde a fonte de gratificação vital”.

No que tange a possibilidade da ocorrência deste dano no direito do trabalho, comumente vislumbramos duas possibilidades: a primeira delas é referente à exigência de uma jornada excessiva pelo empregador, e depois no caso de um ambiente laboral que não assegure ao trabalhador condições mínimas para desfrutar de uma qualidade de vida.

No julgamento do AIRR no 308-86.2012.5.03.0008, Rel. Min. Hugo Carlos Scheuermann, da 1a Turma do TST, publicado em 25 de maio de 2014, ficaram claros os elementos caracterizadores deste dano. Acompanhe:

Constituem elementos do dano existencial, além do ato ilício, o nexo de causalidade e o efetivo prejuízo, o dano à realização do projeto de vida e o prejuízo à vida de relações. Com efeito, a lesão decorrente da conduta patronal ilícita que impede o empregado de usufruir, ainda que parcialmente, das diversas formas de relações sociais fora do ambiente de trabalho (familiares, atividades recreativas e extra laborais), ou seja, que obstrua a integração do trabalhador à 
sociedade, ao frustrar o projeto de vida do indivíduo, viola o direito da personalidade do trabalhador e constitui o chamado dano existencial.

Ainda neste sentido Almeida Neto (2005, p.62) aduz que:

[...] o dano existencial visa proteger a dignidade da pessoa humana, considerando que a ocorrência deste dano causa uma frustração no projeto de vida do ser humano, colocando-o em uma situação de manifesta inferioridade - no aspecto de felicidade e bem-estar - comparada àquela antes de sofrer o dano, sem necessariamente importar em um prejuízo econômico. Mais do que isso, ofende diretamente a dignidade da pessoa, dela retirando, anulando, uma aspiração legítima $[\ldots]$.

Desta forma, para que seja configurado o dano existencial é preciso necessariamente que haja um prejuízo ou frustração no projeto de vida da pessoa, na sua própria existência.

\subsection{Análise jurisprudencial}

Embora timidamente, alguns tribunais já estão reconhecendo este dano, é o que aconteceu no TRT da 4으 Região. 1a turma. Des. Rel. José Felipe Ledur que reconheceu a

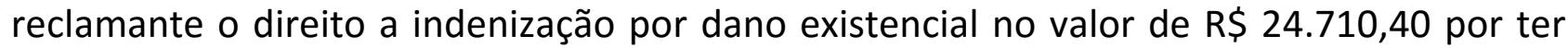
trabalhado mais de oito anos em jornada excessiva (12-13h/d) no RO no 10514/2011.5.04.0241.(Origem: Vara do Trabalho de Alvorada).

DANO EXISTENCIAL. JORNADA EXTRA EXCEDENTE DO LIMITE LEGAL DE TOLERÂNCIA. DIREITOS FUNDAMENTAIS. O dano existencial é uma espécie de dano imaterial, mediante o qual, no caso das relações de trabalho, o trabalhador sofre danos/limitações em relação à sua vida fora do ambiente de trabalho em razão de condutas ilícitas praticadas pelo tomador do trabalho. Havendo a prestação habitual de trabalho em jornadas extras excedentes do limite legal relativo à quantidade de horas extras, resta configurado dano à existência, dada a violação de direitos fundamentais do trabalho que integram decisão jurídicoobjetiva adotada pela Constituição. Do princípio fundamental da dignidade da pessoa humana decorre o direito ao livre desenvolvimento da personalidade do trabalhador, nele integrado o direito ao desenvolvimento profissional, o que exige condições dignas de trabalho e observância dos direitos fundamentais também pelos empregadores (eficácia horizontal dos direitos fundamentais). Recurso provido. (TRT/4a Reg., 1a T. 2011) 
Neste mesmo sentido têm se posicionado os Tribunais Regionais do Trabalho no país. Acompanhe o julgado da 1a Turma do TRT da 3a Região, de relatoria do Des. Paulo Eduardo Queiroz:

DANO EXISTENCIAL. NEGATIVA DE DIREITO AO LAZER E DESCASO. INDENIZAÇÃO PELOS DANOS MORAIS DEVIDA. O direito ao lazer e ao descanso é direito humano fundamental, assegurado constitucionalmente - art. 60 - e está diretamente relacionado com a relação de trabalho. A prorrogação excessiva da jornada de trabalho justifica a indenização compensatória pelo dano causado. Trata-se de desrespeito contínuo aos limites de jornada previstos no ordenamento jurídico, sendo, pois, ato ilícito. É o chamado dano existencial, uma espécie de dano imaterial em que o trabalhador sofre limitações em sua vida fora do ambiente de trabalho. (TRT-3 - RO: 0001924-09.2011.5.03.0113, Relator: Convocado Paulo Eduardo Queiroz Goncalves, Primeira Turma, Data de Publicação: 10/12/2013. DEJT. Página 44. Boletim: Não.)

É importante mencionar, contudo, que para que haja a condenação em dano existencial é preciso que se comprove objetivamente que a jornada excessiva causou prejuízo ao projeto de vida do trabalhador. A mera realização de horas extras não pode dar ensejo a este dano, sob pena da banalização do instituto. Neste sentido também temos o julgados da 1a Turma do TRT da 8a Região, rel. Dra. Suzy Koury. Acompanhe:

\section{[...] 2.2.5 DO DANO EXISTENCIAL.}

Insurge-se a reclamada contra o deferimento de indenização por dano existencial, na importância de $\mathrm{R} \$ 4.000,00$.

Para que haja dano existencial é necessário que a conduta patronal impossibilite o trabalhador de dispor de seu tempo para a execução de projetos de vida, privando-o de se relacionar e de conviver no meio familiar e em sociedade.

Com efeito, a falta de pagamento das horas extras, ora deferidas, não conduz à procedência do pedido de indenização por danos morais, haja vista que, para tanto, devem estar presentes os requisitos delineadores da responsabilidade civil subjetiva, quais sejam, o dano (abalo moral sofrido), a culpa do empregador e o nexo causal entre ambos, que não restaram evidenciados.

De fato, o reclamante não comprovou que, em decorrência do trabalho, fora impossibilitado de usufruir do convívio social e familiar, assim como não indicou nenhum projeto de vida específico, frustrado em razão de ato ilícito da reclamada.

Por assim ser, dou provimento ao apelo para excluir da condenação a indenização deferida. (PROCESSO TRT-8. 1a T./RO 0010493-08.2013.5.08.0010. Rel(a). Des. Dra. Suzy Elizabeth Cavalcante Koury). 
No TST o entendimento também tem se firmado neste sentido, acompanhe o julgamento do Recurso de Revista nos autos do processo no 154-80.2013.5.04.0016 - 4a

Turma. Rel. Min. João Oreste Dalazen:

RECURSO DE REVISTA. DANO EXISTENCIAL. PRESSUPOSTOS. SUJEIÇÃO DO EMPREGADO A JORNADA DE TRABALHO EXTENUANTE. JORNADAS ALTERNADAS 1. A doutrina, ainda em construção, tende a conceituar o dano existencial como o dano à realização do projeto de vida em prejuízo à vida de relações. $O$ dano existencial, pois, não se identifica com o dano moral. 2. O Direito brasileiro comporta uma visão mais ampla do dano existencial, na perspectiva do art. 186 do Código Civil, segundo o qual "aquele que por ação ou omissão voluntária, negligência ou imprudência, violar direito e causar dano a outrem, ainda que exclusivamente moral, comete ato ilícito". A norma em apreço, além do dano moral, comporta reparabilidade de qualquer outro dano imaterial causado a outrem, inclusive o dano existencial, que pode ser causado pelo empregador ao empregado, na esfera do Direito do Trabalho, em caso de lesão de direito de que derive prejuízo demonstrado à vida de relações. 3. A sobrejornada habitual e excessiva, exigida pelo empregador, em tese, tipifica dano existencial, desde que em situações extremas em que haja demonstração inequívoca do comprometimento da vida de relação. 4. A condenação ao pagamento de indenização por dano existencial não subsiste, no entanto, se a jornada de labor exigida não era sistematicamente de 15 horas de trabalho diárias, mas, sim, alternada com jornada de seis horas diárias. Robustece tal convicção, no caso, a circunstância de resultar incontroverso que o contrato de trabalho mantido entre as partes perdurou por apenas nove meses. Não se afigura razoável, assim, que nesse curto período a conduta patronal comprometeu, de forma irreparável, a realização de um suposto projeto de vida em prejuízo à vida de relações do empregado. 5. Igualmente não se reconhece dano existencial se não há demonstração de que a jornada de trabalho exigida, de alguma forma, comprometeu irremediavelmente a vida de relações do empregado, aspecto sobremodo importante para tipificar e não banalizar, em casos de jornada excessiva, pois virtualmente pode consultar aos interesses do próprio empregado a dilatação habitual da jornada. Nem sempre é a empresa que exige o trabalho extraordinário. Em situações extremas, há trabalhadores compulsivos, ou seja, viciados em (workaholic), quer motivados pela alta competitividade, vaidade, ganância, necessidade de sobrevivência, quer motivados por alguma necessidade pessoal de provar algo a alguém ou a si mesmo. Indivíduos assim geralmente não conseguem desvincular-se do trabalho e, muitas vezes por iniciativa própria, deixam de lado filhos, pais, amigos e família em prol do labor. Daí a exigência de o empregado comprovar que o empregador exigiu-lhe labor excessivo e de modo a afetar-Ihe a vida de relações. 6 . Recurso de revista conhecido e provido.

Assim, vislumbra-se ainda que timidamente a possibilidade da condenação por dano existencial quando configurada uma lesão ao plano de vida da pessoa, a sua existência. 


\subsection{Diferenças entre dano moral e dano existencial}

Note-se que para a correta reparação da vítima pelo dano sofrido é preciso que se faça a distinção entre dois danos: o moral e o existencial.

Embora sejam espécies do mesmo gênero (dano de natureza extrapatrimonial), estes danos não se confundem, pois o objeto de proteção de ambos é bastante distinto. 0 dano existencial prejudica o projeto de vida da pessoa, enquanto que o dano moral consiste em uma lesão na esfera subjetiva do indivíduo, no aspecto interno, íntimo, pessoal.

A distinção entre dano existencial e o dano moral reside no fato de este ser essencialmente um sentir, e aquele um não mais poder fazer, um dever de agir de outra forma, um relacionar-se diversamente em que ocorre uma limitação do desenvolvimento normal da vida da pessoa. Nesse sentido, enquanto o dano moral incide sobre o ofendido, de maneira, muitas vezes, simultânea à consumação do ato lesivo, o dano existencial, geralmente, manifesta-se e é sentido pelo lesado em momento posterior, porque ele é uma sequência de alterações prejudiciais no cotidiano, sequência essa que só o tempo é capaz de caracterizar (SOARES, 2009, p. 46).

Ante o acima é importante mencionar que embora haja uma significativa diferença entre essas duas espécies de dano, alguns magistrados, no julgamento de casos concretos veem confundindo tais danos, tratando o dano existencial como uma espécie de dano moral, ou como "dano moral existencial", o que prejudica, e banaliza, a relevância desse instituto jurídico para a proteção da dignidade do trabalhador. Foi exatamente a retificação feita pela Rel. Des. Dra. Pastora Leal no julgamento do RO no 0002161.22.2013.5.08.0117. No caso em análise, o acórdão da $4 \underline{a}$ Turma do TRT da 8 $\underline{a}$ Região, manteve a sentença de primeiro grau que condenou o empregador a indenizar a trabalhadora por "danos morais", sob o fundamento de que houve ofensa à sua honra objetiva, pela não concessão de férias durante todo o pacto laboral, que totalizou 14 anos. Em 2 o grau houve a correção da sentença para reconhecer que estávamos diante de dano existencial. Acompanhe o julgado: 
EMENTA: NÃO CONCESSÃO DE FÉRIAS DURANTE TODO O PACTO LABORAL (14 ANOS). PREJUÍZO À VIDA SOCIAL DO TRABALHADOR. DANO EXISTENCIAL. CONFIGURAÇAO. Demonstrada a conduta contumaz da empresa em não permitir que a trabalhadora usufruísse de férias anuais, direito constitucionalmente assegurado, que além de visar à proteção da integridade física, mental e moral do empregado, possibilita que o mesmo usufrua do convívio social e familiar, que tenha lazer, que participe de atividades educativas e/ou religiosas, etc, forçoso é reconhecer que a empresa causou dano à vida em sociedade de sua exempregada, provocando um vazio existencial em sua pessoa. Destarte, caracterizado o ato ilícito da empregadora, é devida a reparação civil, nos termos

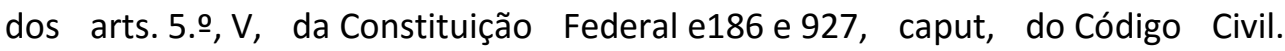
Mantida a d. sentença. Recurso improvido.

Defendemos inclusive a possibilidade de cumulação desses dois danos quando há ao mesmo tempo ofensa a objetos distintos: a personalidade e ao projeto de vida do trabalhador. Este também foi o entendimento da 2a Turma do TRT da 9a Região, no processo de Relatoria da Des. Dra. Ana Carolina Zaina.

DANO EXISTENCIAL. DANO MORAL. DIFERENCIAÇÃO. CARGA DE TRABALHO EXCESSIVA. FRUSTRAÇÃO DO PROJETO DE VIDA. PREJUÍZO À VIDA DE RELAÇÕES. O dano moral se refere ao sentimento da vítima, de modo que sua dimensão é subjetiva e existe in re ipsa, ao passo que o dano existencial diz respeito às alterações prejudiciais no cotidiano do trabalhador, quanto ao seu projeto de vida e suas relações sociais, de modo que sua constatação é objetiva. Constituem elementos do dano existencial, além do ato ilícito, o nexo de causalidade e o efetivo prejuízo, o dano à realização do projeto de vida e o prejuízo à vida de relações. Caracteriza-se o dano existencial quando o empregador impõe um volume excessivo de trabalho ao empregado, impossibilitando-o de desenvolver seus projetos de vida nos âmbitos profissional, social e pessoal, nos termos dos artigos 60 e 226 da Constituição Federal. 0 trabalho extraordinário habitual, muito além dos limites legais, impõe ao empregado o sacrifício do desfrute de sua própria existência e, em última análise, despoja-o do direito à liberdade e à dignidade humana. Na hipótese dos autos, a carga de trabalho do autor deixa evidente a prestação habitual de trabalho em sobrejornada excedente ao limite legal, o que permite a caracterização de dano à existência, eis que é empecilho ao livre desenvolvimento do projeto de vida do trabalhador e de suas relações sociais. Recurso a que se dá provimento para condenar a ré ao pagamento de indenização por dano existencial. (TRT-PR-28161-2012-028-09-00-6-ACO-40650-2013 - 2A. TURMA - Relator: ANA CAROLINA ZAINA - Publicado no DEJT em 11-10-2013).

Desta forma, percebe-se que este é o entendimento que tem prevalecido nos Tribunais do país. 


\section{CONSIDERAÇÕES FINAIS}

É necessário se fazer uma nova interpretação do ordenamento jurídico brasileiro, pois é preciso adotar a concepção da penetração dos direitos fundamentais nas relações privadas, especialmente nos direitos trabalhistas. Precisamos considerar o direito ao trabalho como um direito fundamental social, e também como um direito humano.

Os direitos trabalhistas são protetivos ao trabalhador. Não adianta ter o direito ao trabalho, e permitir que ele seja lesionado, e compensado economicamente. Não basta apenas a reparação pecuniária, essas questões afetam a vida do trabalhador, a sua existência e a sua condição humana.

Devemos respeitar a dignidade da pessoa humana no ambiente laboral. Eis o papel do direito do trabalho: proteger os direitos básicos dos trabalhadores de modo a assegurar-lhes um trabalho digno, com qualidade, sem extrapolar os limites estabelecidos pelo ordenamento jurídico vigente, respeitando a sua dignidade como ser humano, e consequentemente, os seus direitos fundamentais.

Assim é necessário o reconhecimento da eficácia horizontal dos direitos fundamentais nas relações privadas de trabalho, para evitar superexploração do empregador, a coisificação do homem. Do contrário, estaremos diante de uma situação de precarização das normas sociais já consagradas pelo ordenamento jurídico, o que violaria inclusive um dos princípios básicos de nosso ordenamento jurídico: como o Princípio do não retrocesso social.

O homem não pode ser colocado a serviço da economia, é esta que deve ser estruturada de forma a melhorar a existência humana.

Sempre que o empregador exigir do empregado uma produtividade inalcançável ou quando o trabalho causar prejuízo à existência humana, ao lazer, ao desenvolvimento do plano de vida do trabalhador, ou a sua saúde, estaremos diante de fatores aptos a ensejarem a condenação do empregador por causar ao trabalhador um dano existencial. 


\section{REFERÊNCIAS}

ABRANTES, José João. Contrato de Trabalho e direitos fundamentais. Coimbra: Almedina, 2005.

ALMEIDA, Almiro Eduardo de; SEVERO, Valdete Souto. Direito à desconexão nas relações sociais de trabalho. São Paulo: LTr, 2015.

ALMEIDA NETO, Amaro Alves de. Dano existencial: a tutela da dignidade da pessoa humana. In: Revista dos Tribunais, São Paulo, v. 6, n. 24, mês out/dez, 2005.

ALVARENGA, Rúbia Zanotelli de; BOUCINHAS FILHO, Jorge Cavalcanti. O dano existencial e o direito do trabalho. In: RDT - Revista de direito trabalhista. Brasília: Consulex. Ano XIX mar 2013, p. 32-38.

AMARAL, Julio Ricardo de Paula. Eficácia dos direitos fundamentais nas relações de trabalho. 2 ed. São Paulo: LTr. 2014.

BATISTA, Márcio Oliveira. A regulação do direito ao lazer no resgate da dignidade humana do trabalhador e sua formação social. In: ALMEIDA, Roberto Ribeiro de; CRUZ, Priscila Aparecida Silva; ALVES, Marianny (Org.). Direitos Humanos em um contexto de desigualdades. São Paulo: Boreal, 2012.

BEBBER, Júlio Cézar. Danos extrapatrimoniais (estético, biológico e existencial): breves considerações. In: Revista LTr, São Paulo, v. 73, n. 1, jan. 2009.

BRANCO, Paulo Gustavo Gonet; MENDES, Gilmar Ferreira. Curso de Direito Constitucional. 7ạ ed. São Paulo: Saraiva, 2012.

BRASIL. Constituição (1988) Constituição da República Federativa do Brasil de 1988. Brasília, DF $\quad$ Senado, $1988 . \quad$ Disponível em: <http://www.planalto.gov.br/ccivil_03/constituicao/constituicao.htm>. Acesso em: 02 jun. 2015.

BRASIL. Consolidação das Leis do Trabalho. Decreto no 5.452 de 1o de maio de 1943. Aprova a consolidação das leis do trabalho. Diário Oficial da União, Brasília, CF, 09 ago. 1943. Disponível em: <http://www.planalto.gov.br/ccivil_03/decreto-lei/del5452.htm>. Acesso em: 17 jun. 2015.

BRASIL. TRT-1. Tribunal Regional do Trabalho. 10 Fórum de Direito Material e Processual do Trabalho do Tribunal Regional do Trabalho da $1 \underline{a}$ região. s.d.a Disponível em: 
<http://www.trt1.jus.br/documents/10157/998278/1FORUM_PDF.pdf>. Acesso em: 16 jun. 2015.

BRASIL. TRT-4. Tribunal Regional do Trabalho. Recurso Ordinário n 10514/2011.5.04.0241. Relator: Desembargador José Felipe Ledur, 1a Turma. Julgado em: 14 mar. 2012. Disponível em: <http//: www.trt4.jus.br>.

BRASIL. TRT-9. Tribunal Regional do Trabalho. Recurso Ordinário no 28161-2012-028-0900-6-ACO-40650-2013. Relator: Des. Dra. Ana Carolina Zain. 2a Turma. Publicado no DEJT em 11 out. 2013. Disponível em: www.trt9.jus.br. Acesso em: 11 jun. 2015.

BRASIL. TRT-8. Tribunal Regional do Trabalho. RO no 0010493-08.2013.5.08.0010. Rel(a). Des. Dra. Suzy Elizabeth Cavalcante Koury. 1a Turma. Disponível em www.trt8.jus.br. Acesso em: 11 jun. 2015.

BRASIL. TST. Tribunal Superior do Trabalho. Recurso de Revista $\mathrm{n}$ 0 154-80.2013.5.04.0016. Rel. Min. João Oreste Dalazen. 4a Turma. Disponível em www.tst.jus.br/jurisprudencia. Acesso em: 11 jun. 2015.

BRITO FILHO, José Cláudio Monteiro de. Trabalho Decente: análise jurídica da exploração do trabalho - trabalho escrevo e outras formas de trabalho indigno. 3a ed. São Paulo: LTr, 2013.

CALVET, Otávio. Direito ao lazer nas relações de trabalho. São Paulo: LTr, 2006.

CIFUENTES MUÑOZ, Eduardo. La eficacia de los derechos fundamentales frente a particulares. México: Universidade Nacional Autônoma de México, 1998.

DUARTE, Bernardo Augusto Ferreira. Levando o direito ao lazer à sério. In: Revista do Tribunal de Contas do Estado de Minas Gerais. V.27. no 4. 2009. p.73-96.

ESPANHA. Tribunal Constitucional da Espanha. Sentenças n. 101/1981, de 18 de novembro. Sentença n. 177/1988, de 10 de outubro. Disponível em: www.tribunalconstitucional.es. Acesso em 20 de jul. 2015.

FRANCO, Georgenor de Sousa. O direito social à felicidade. In: Direitos Fundamentais: questões contemporâneas. Em homenagem aos 25 anos da Constituição Federal de 1988. Rio de Janeiro: GZ editora. 2014.

FROTA, Hidemberg Alves da. Noções fundamentais sobre dano existencial. In: Revista eletrônica do Tribunal Regional do Trabalho do Paraná. v 2. n 22. Set - 2013.

MORAES, Maria Celina Bodin. Danos à pessoa: uma leitura civil-constitucional dos danos morais. Rio de Janeiro: Renovar, 2003. 
SARMENTO, Daniel. Livres e Iguais: estudos de direito constitucional. Rio de Janeiro: Lumen Juris. 2006.

. Direitos fundamentais e relações privadas. Rio de Janeiro: Lumens Juris, 2004.

SOARES, Flaviana Rampazzo. Responsabilidade civil por dano existencial. Porto Alegre: Livraria do Advogado, 2009.

FERREIRA, Vanessa Rocha. O dano existencial nas relações de trabalho e a eficácia horizontal dos direitos

fundamentais nas relações privadas. RBSD - Revista

Brasileira de Sociologia do Direito, v. 3., n. 1, p. 97-116,

jan./abr. 2016.

Recebido em: 27/07/2016

Aprovado em: 03/08/2016 